\title{
HIRES, SEPARATIONS, AND THE JOB TENURE DISTRIBUTION IN ADMINISTRATIVE EARNINGS RECORDS*
}

by

\author{
Henry R. Hyatt \\ U.S. Census Bureau
}

James R. Spletzer

U.S. Census Bureau

CES 14-29 September, 2014

The research program of the Center for Economic Studies (CES) produces a wide range of economic analyses to improve the statistical programs of the U.S. Census Bureau. Many of these analyses take the form of CES research papers. The papers have not undergone the review accorded Census Bureau publications and no endorsement should be inferred. Any opinions and conclusions expressed herein are those of the author(s) and do not necessarily represent the views of the U.S. Census Bureau. All results have been reviewed to ensure that no confidential information is disclosed. Republication in whole or part must be cleared with the authors.

To obtain information about the series, see www.census.gov/ces or contact Fariha Kamal, Editor, Discussion Papers, U.S. Census Bureau, Center for Economic Studies 2K132B, 4600 Silver Hill Road, Washington, DC 20233, CES.Papers.List@census.gov. 


\begin{abstract}
Statistics on hires, separations, and job tenure have historically been tabulated from survey data. In recent years, these statistics are increasingly being produced from administrative records. In this paper, we discuss the calculation of hires, separations, and job tenure from quarterly administrative records, and we present these labor market statistics calculated from the U.S. Census Bureau's Longitudinal Employer-Household Dynamics (LEHD) program. We pay special attention to a phenomenon that survey data is ill-suited to analyze: single quarter jobs, which we define as jobs in which the hire and separation occur in the same quarter. We explore the trends of hires, separations, tenure, and single quarter jobs in the United States for the years 1998-2010. We discuss issues associated with creating these statistics from quarterly earnings records, and we identify the challenges that remain.
\end{abstract}

Keyword: hires; separations; tenure; administrative records

\footnotetext{
* Any opinions and conclusions expressed herein are those of the author(s) and do not necessarily represent the views of the U.S. Census Bureau. All results have been reviewed to ensure that no confidential information is disclosed.
} 


\section{Introduction}

Statistics on hires (also called accessions), separations, and job tenure (also called job duration, or seniority) provide information about labor market dynamics and whether employment in the U.S. has become more or less stable over time. Data sources that have historically given us information on these labor market statistics for the U.S. have been the Panel Study of Income Dynamics (PSID), the Job Openings and Labor Market Turnover Survey (JOLTS), and supplements to the Current Population Survey (CPS). Statistics calculated from these surveys are invaluable for analysis, but are limited by relatively small sample sizes, and, in the case of the PSID and the CPS supplements, by the annual or biennial nature of the survey collection cycle. Statistics calculated from administrative records on individuals' employment are now enhancing and perhaps supplanting statistics produced from survey data.

In the U.S., the Census Bureau's Longitudinal Employer-Household Dynamics (LEHD) program has been using administrative records to produce labor market statistics for many years. The LEHD administrative records are essentially a universe of privatesector jobs, and this jobs-based data (rather than person-based data) allows a more comprehensive understanding of hires, separations, and job tenure than has previously been available from survey data. Jobs-based data also highlight two special phenomena that are often glossed over when using person-based data: single quarter jobs, defined as jobs that begin and end in the same quarter, and the importance of multiple jobholding Both of these influence the calculation and the interpretation of hires, separations, and tenure statistics. .

In this paper, we review how hires and separations statistics are calculated from the administrative earnings records of the LEHD, and we describe how to calculate tenure statistics from the LEHD data. We also provide a summary of the evidence that these data have provided so far for the years 1998-2010. 


\section{Data}

The LEHD is a longitudinally linked employer-employee dataset created by the U.S. Census Bureau as part of the Local Employment Dynamics federal-state partnership. The data are derived from state-submitted Unemployment Insurance (UI) wage records and the Quarterly Census of Employment and Wages (QCEW) data. Every quarter, employers who are subject to state UI laws -- approximately $98 \%$ of all private sector employers, plus state and local governments -- submit to the states information on their workers (the wage records, which lists the quarterly earnings of every individual in the firm) and their workplaces (the QCEW, which provides information on the industry and location of each establishment). The wage records and the QCEW data submitted by the states to the U.S. Census Bureau are enhanced with census and survey microdata in order to incorporate information about worker demographics (age, gender, race and ethnicity, and education) and the firm (firm age and firm size).

Abowd et al. (2009) provide a thorough description of the source data and the methodology underlying the LEHD data and one of its main public use data products, the Quarterly Workforce Indicators (QWI). The QWI data products published by the LEHD program at the U.S. Census Bureau are available at http://lehd.ces.census.gov, and include tabulations of economic indicators such as employment, earnings, hires, separations, job creation, and job destruction by geographies, by firm characteristics, and by individual characteristics. Because states have joined the LEHD program at different times, and have provided various amounts of historical data upon joining the LEHD program, the length of the time series of LEHD data varies by state. For all the figures presented in this paper, we use public-use data from 30 states that have data available from 1998:Q2 through 2010:Q4; these 30 states account for 65 percent of national employment. ${ }^{1}$

All figures in this paper are created using the LEHD public-use statistics described in Abowd et al. (2009). Additionally, the work reported in Hyatt and Spletzer (2013, 2014), which is summarized in this paper, relies on additional infrastructure files related to the job-to-job flows data described in Hyatt and McEntarfer (2012), and on firm age and size data described in Haltiwanger et al. (2014). The job-to-job flows data link employers over time who employ a given worker in consecutive maximum-earnings jobs, and allow comprehensive statistics that are person-based, whereas most regularly produced LEHD statistics are job-based. This distinction matters because workers can, and many do, hold multiple jobs. The data on firm age and size reflect a recent enhancement that links comprehensive national firm-level information (using information

\footnotetext{
1 These 30 states are: CA, CO, CT, FL, GA, HI, ID, IL, IN, KS, LA, MD, ME, MN, MO, MT, NC, ND, NJ, NM, NV, PA, RI, SC, SD, TN, TX, VA, WA, and WV. Hyatt and Spletzer (2013) state that the magnitude of the decline in employment dynamics computed from the 30 states is essentially the same as the magnitude computed from the national series of LEHD statistics constructed by Abowd and Vilhuber (2011).
} 
on common operational control for employers with different identifiers) to LEHD employers, which are identified at the state level.

\section{Conceptual Framework}

In this section, we define concepts precisely as they follow from tabulations of the data. The definitions follow from Abowd et al. (2009). A "job" is defined as a unique employer-employee combination that occurs in one or more consecutive quarters. ${ }^{2}$ A hire can be written as a case in which a worker has earnings recorded at a given employer in a quarter, but not in the previous quarter. So, for worker $i$, firm $j$, and time $t$, a hire (accession) is defined by

$$
a_{i j t}=\left\{\begin{array}{l}
1, \text { if } w_{i j t}>0, w_{i j t-1}=0 \\
0, \text { otherwise }
\end{array} .\right.
$$

Likewise, at time $t$, a separation is defined by

$$
s_{i j t}=\left\{\begin{array}{l}
1, \text { if } w_{i j t}>0, w_{i j t+1}=0 \\
0, \text { otherwise }
\end{array} .\right.
$$

We also define a single-quarter job. This is a job where the separation and the hire occur in the same quarter. In other words,

$$
s q j_{i j t}=\left\{\begin{array}{l}
1, \text { if } a_{i j t}=1, s_{i j t}=1 \\
0, \text { otherwise }
\end{array}\right.
$$

More generally, at time $t$, a job has tenure (duration $\mathrm{d}$ ) $\mathrm{k}$ based upon the following definition:

$$
d_{i j t}^{k}=\left\{\begin{array}{l}
1, \text { if } a_{i j t-k}=1 \text { and } w_{i j \tau}>0 \text { for all } \tau=\{t-k, \ldots, t\} \\
0, \text { otherwise }
\end{array} .\right.
$$

Tenure is defined as the number of previous quarters with the employer, which explains why individuals hired this quarter have tenure equal to zero. This is similar to the concept of human age, where newborns have an age of zero during their first year.

\section{The Job Tenure Distribution}

Hires and separations have a natural relationship with job tenure as each job spell begins with a hire and ends with a separation. We frame this relationship through a simple model of the evolution of tenure in the spirit of Neumark, Polsky, and Hansen (1999). At time t, the tenure $\mathrm{k}$ indicator, $d_{i j t}^{k}$, can be written as the product of the hires indicator in the appropriate previous time period times the tenure-specific separation indicators for each time thereafter:

2 Throughout this paper, recalls to a job after an extended absence are considered to be new jobs. In the concluding section of this paper, we discuss ongoing work to incorporate such recalls into measures of hires and separations. 


$$
d_{i j t}^{k}=\left\{\begin{array}{l}
a_{i j t}, \text { if } k=0 \\
a_{i j t-k} * \prod_{\tau=1}^{k}\left(1-s_{i j t-\tau}^{k-\tau}\right), \text { if } k \geq 1
\end{array}\right.
$$

where the tenure-specific separations indicator, $s_{i j t-\tau}^{k-\tau}$, is defined as

$$
s_{i j t-\tau}^{k-\tau}=\left\{\begin{array}{l}
1, \text { if } s_{i j t-\tau}=1 \text { and } d_{i j t-\tau}^{k-\tau}=1 \\
0, \text { otherwise }
\end{array}\right. \text {. }
$$

Equation (5) defines tenure $\mathrm{k}$ for a specific job in the longitudinally linked microdata, and the distribution of tenure in a given quarter $t$ can be defined by summing over all jobs in that quarter. However, it is often more convenient to work with macrolevel tabulations. Define $E_{t}$ as the size of the workforce in quarter $t$. The number of jobs of tenure $k$ can be written as a function of the size of the workforce, $E_{t-k}$, the hiring rate $A R_{t-k} \equiv \frac{\sum_{i, j} a_{i, j, t-k}}{E_{t-k}}$, and the tenure-specific separation rates $S R_{t-\tau}^{k-\tau} \equiv \frac{\sum_{i, j} s_{i, j, t-\tau} d_{i j t-\tau}^{k-\tau}}{\sum_{i, j} d_{i j t-\tau}^{k-\tau}}$. In quarter $\mathrm{t}$, the number of jobs of tenure $\mathrm{k}, D_{t}^{k}$, is:

$$
D_{t}^{k}=\left\{\begin{array}{l}
E_{t} * A R_{t}, \quad \text { if } k=0 \\
E_{t-k} * A R_{t-k} * \prod_{\tau=1}^{k}\left(1-S R_{t-\tau}^{k-\tau}\right), \text { if } k \geq 1
\end{array} .\right.
$$

\section{Empirical Findings}

This section reviews the evidence on the trends in hires, separations, single quarter jobs, and job tenure in the U.S. for the years 1998-2010. We show that over this time period, the hire and separation rates declined, the incidence of single quarter jobs declined, and the tenure distribution shifted toward longer duration jobs. These results review those from Hyatt and Spletzer $(2013,2014)$, as well as our work in progress.

\section{Hires and Separations}

Figure 1, which is from Hyatt and Spletzer (2013), presents the seasonally adjusted quarterly rates of hires and separations from three different data sources: the LEHD, the Current Population Survey (CPS), and the Job Openings and Labor Turnover survey (JOLTS). As described in Hyatt and Spletzer (2013), all three series are from publicly-available data. A secular decline in hires and separations is obvious in all three series. This is indicative of a broader decline in measures of employment reallocation, with declines also apparent in job creation and job destruction (net job growth due to business expansion, contraction, entry, and exit), as well as job-to-job flows.

In Figure 1, the levels of hires and separations are clearly different across the three data sources (LEHD, CPS, JOLTS). Hyatt and Spletzer (2013) discuss these level differences and conclude that they are not of serious concern. The three series do not precisely measure the same thing - for example, the LEHD measures hires and separations across all jobs, whereas the CPS measures hires and separations only for the individual's main job. Furthermore, there is evidence that the LEHD has more shortduration jobs than does the CPS (see Abraham et al. 2013), and this would lead to higher LEHD hires and separations rates. There is also evidence that the JOLTS misses establishments with large amounts of dynamics (see Davis et al. 2010), which would lead to lower JOLTS hires and separations rates. More importantly, we see declining rates of 
hires and separations in all three datasets, albeit varying amounts of decline. These declines are not sensitive to the endpoints of the time period; declines are obvious in Figure 1 from any point in the late 1990s (excepting the JOLTS, which starts in 2001:Q1) to any point in the early 2010s. Over the time period 1998:Q2 to 2010:Q4, hires and separations rates have declined by 37\% in the LEHD, 31\% in the JOLTS (starting in 2001:Q1), and 11\% in the CPS. The declines in hires and separations from all three data sources show a "stair-step" pattern, with declines concentrated in or around recessions, from which the measures never fully recover during expansions. Using NBER recession dates, all of the 8.9 percentage point decline in LEHD hires (from 2001:Q1 - 2010:Q4) occurs during the 2001 and the 2007-2009 recessions, and 6.3 percentage points of the 8.1 percentage point decline in LEHD separations occurs during the recessionary quarters.

One of the main conclusions from Hyatt and Spletzer (2013) is that secular changes in demographic and job characteristics can not explain much of the decreasing trends in hire and separation rates (nor can the changes in composition explain much of the decreasing trends in job creation, job destruction, or job-to-job flow rates). For example, the aging of the baby boom has shifted the composition of the workforce towards older workers during the 2000s, and older workers have lower hire and separation rates than younger workers, but this compositional shift only explains about 12 percent of the decline of the LEHD hire and separation rates. Furthermore, compositional changes in employer characteristics such as firm age or firm size explain relatively little of the decline in the hires and separations rates.

\section{Single Quarter Jobs}

We next explore the trends in a phenomenon that the LEHD administrative records are especially suited to examine: single quarter jobs. ${ }^{3}$ Single quarter jobs are defined as jobs that begin and end in the same quarter. Figure 2 shows that the incidence of single quarter jobs fell from 11.4 percent in 1998:Q4 to 6.0 percent in 2010:Q3. This decline follows the stair-step pattern evident in Figure 1, where the declines are concentrated during and around the recessions of 2001 and 2007-2009. Single quarter jobs are important to understanding the recent decline in hires and separations - Hyatt and Spletzer (2013) show that the decline of single quarter jobs accounts for half of the decline in overall hires and separations. This is obvious in Figure 2, since the overall hires rate in Figure 1 is the sum of the hires rate into single quarter jobs plus the hires rate into jobs that last two or more quarters, and the overall separations rate in Figure 1 is the sum of the separations rate from single quarter jobs plus the separations rate from jobs that last two or more quarters.

The following analysis of single quarter jobs (also referred to as short duration jobs) is based upon Hyatt and Spletzer's (2014) analysis of confidential LEHD

\footnotetext{
3 The LEHD program does not specifically tabulate single-quarter jobs, but they can be obtained from the following formula (using the notation of Abowd et.al, 2009):

$$
S D J=M-(B-F)-(E-F)-F
$$

where $M$ is the number of employee-employer combinations in the quarter, $B$ is the number of consecutivequarter jobs at the beginning of the quarter, $E$ is the number of consecutive-quarter jobs at the end of the quarter, and $F$ is the number of full-quarter jobs. Each of these components are available from public-use LEHD tabulations.
} 
microdata. There are two "types" of single quarter jobs: there are individuals who hold one or more single quarter jobs in a quarter without simultaneously holding a longer duration job, and there are individuals who simultaneously hold both a single quarter job and a longer duration job. Both types exist (roughly 50/50 in the late 1990s), and both types are declining over time. As shown by Hyatt and Spletzer (2014), the decline of single quarter jobs is accompanied by a simultaneous and much larger decline in longer duration jobs. This implies that the decline in single quarter jobs was not accompanied by a switch of persons from single quarter jobs to longer duration jobs. Furthermore, the decline in single quarter jobs plays only a small role in explaining the recent decline in the employment-to-population ratio.

\section{The Job Tenure Distribution}

Just as there is a relationship between the decline in single quarter jobs and the declining hires and separations rates, there is also a relationship between the decline in single quarter jobs and the tenure distribution. By definition, a secular decline in the percentage of jobs with completed duration less than one quarter will shift the tenure distribution to the right. Furthermore, equation (7) above shows that the declining hires and separations rates will also influence the tenure distribution.

According to equation (7), estimating the complete tenure distribution requires tenure-specific separation rates for all levels of tenure k. However, the LEHD program at the Census Bureau does not publish tenure-specific separation rates, and thus estimating the full tenure distribution requires longitudinal matched employer-employee microdata. Although a comprehensive view of the entire tenure distribution is desired (tabulations of the entire tenure distribution using the confidential LEHD microdata are ongoing but are not yet ready for publication), the first several quarters of the tenure distribution can be estimated using publicly available LEHD statistics.

Using the notation above, we can estimate the tenure-specific separation rates for jobs in their first quarter of tenure $\left(S R_{t}^{0}\right)$, as well as for jobs with one quarter of previous tenure $\left(S R_{t}^{1}\right){ }^{4}$ These two tenure-specific separation rates, along with the hiring rate, are graphed in Figure 3. There has been a clear downward trend in these two separation rates. We note that the separations rate for jobs with one completed quarter of tenure $\left(\mathrm{SR}^{1}\right)$ exceeds the separations rate for nascent jobs $\left(\mathrm{SR}^{0}\right)$; this finding is different from the evidence cited by Farber (1999) and warrants further analysis.

With knowledge of $S R_{t}^{0}$ and $S R_{t}^{1}$, we can estimate the tenure distribution for the first three quarters of tenure: $D_{t}^{0}, D_{t}^{1}$, and $D_{t}^{2}$. We estimate the employment shares using equation (7). ${ }^{5}$ Furthermore, since all tenure shares must sum to one, we can also estimate $D_{t}^{3+}$, which is the share of employment with three or more quarters of tenure. These tenure shares are shown in Figure 4. There has been a pronounced downward trend in $D_{t}^{0}, D_{t}^{1}$, and $D_{t}^{2}$ during the 1998 to 2010 time period. As a share of employment, newly obtained jobs $\left(\mathrm{D}^{0}=\right.$ hires$)$ have fallen from 29 percent in the late 1990 s to 18 percent in 2010. Jobs with one quarter of completed tenure $\left(D^{1}\right)$ have fallen from 17 percent to 12

${ }^{4}$ Using the notation of Abowd et.al, (2009), $S R^{0}=1-\left[\frac{E-F}{A R *\left(\frac{B+E}{2}\right)}\right]$ and $S R^{1}=1-\left[\frac{F A R * F}{E-F}\right]$.

${ }^{5}$ The employment shares are $\left(\frac{D_{t}^{0}}{E_{t}}\right)=A R_{t},\left(\frac{D_{t}^{1}}{E_{t}}\right)=\left(\frac{E_{t-1}}{E_{t}}\right) A R_{t-1}\left(1-S R_{t-1}^{0}\right)$, and

$\left(\frac{D_{t}^{2}}{E_{t}}\right)=\left(\frac{E_{t-2}}{E_{t}}\right) A R_{t-2}\left(1-S R_{t-2}^{0}\right)\left(1-S R_{t-1}^{1}\right)$. 
percent, and jobs with two quarters of completed tenure $\left(\mathrm{D}^{2}\right)$ have fallen from 9 percent to 7 percent. These declines are offset by an increase in the percent of jobs with three or more quarters of previous tenure $\left(\mathrm{D}^{3+}\right)$ : as a share of employment, these jobs have risen from 45 percent in the late 1990s to 64 percent in 2010. This rise in the relative percent of high-tenured jobs occurs during and around recessions, which mimics the "stair-step" decline observed in the hire and separation rates, as well as the "stair-step" decline observed in the single-quarter jobs rate. A complete analysis of the driving forces underlying the observed shifts in the tenure distribution is the focus of our current ongoing work.

\section{Outstanding Issues in Creating Tenure Statistics}

Figures 3 and 4 are based on publicly available data. Our ongoing analysis of restricted-use LEHD microdata will allow us to obtain a more complete tenure distribution beyond the first several quarters presented in this paper. Specifically, we are estimating tenure-specific separation rates, and thus the tenure shares $\left(D^{k} / E\right)$, for $k=20$ quarters. This analysis of confidential microdata will also allow us to control for four potentially important issues. All four issues arise from computing tenure statistics from administrative jobs-level microdata rather than the conventional person-based data.

First, multiple job holding is an issue for measuring job tenure. For example, in the person-based CPS, respondents are asked about their time with their main job. Calculation of person-level employment statistics in jobs-based administrative records was recently done in the job-to-job flows project, see Hyatt and McEntarfer (2012). As described in Hyatt and McEntarfer, the straightforward unidirectional approach to job tenure described in this paper does not hold uniquely at the person level, as workers may separate from a job and their main source of earnings may come from a job that was previously secondary. The solution implemented by Hyatt and McEntarfer was to reduce the dimensionality of the problem around a "maximal earnings" concept.

Second, there is also the issue of time aggregation and continuous time adjustment. We miss short spells of unemployment. Note that corrections often assume that transitions are duration independent, which may be at odds with the data.

Third, we also are only at the beginning of dealing with recalls. We need to distinguish between hires that are recalls to a previous employer (within a reasonable timeframe) versus hires to an employer that the individual never worked for in the past. This may be particularly important, as recalls have their own cyclical properties; see Fujita and Moscarini (2013).

Fourth, one of the main methodological issues in creating longitudinal statistics from cross-sectional administrative earnings records is the identification of successorpredecessor relationships; see Benedetto et al. (2007). This is the phenomenon in which an employer may change its tax identifier, which makes it appear as though a sizeable proportion of workers separate from one employer and simultaneously are hired by a different employer. Successor-predecessor relationships also include scenarios in which a firm makes a divestment that induces a number of employees to move to a new employer, as well as merger and acquisition activity. Historically, successor-predecessor relationships have been systematically integrated into the Quarterly Workforce Indicators, but have not been identified at an interval for multiple years from any given reference point. The LEHD infrastructure files have been enhanced with a Person 
History Enhanced Across SEIN and Non-SEIN Transitions (PHEASANT) file in order to control for successor-predecessor relationships across extended periods of time; this PHEASANT file will dramatically improve the quality of LEHD statistics that document long-term relationships such as tenure.

\section{Conclusions}

We have described how hires, separations, single quarter jobs, and job tenure can be calculated as straightforward tabulations of longitudinally linked matched employeremployee data produced and maintained by the U.S. Census Bureau's LEHD program. We defined these measures and explored their relationship to one another.

We then reviewed the evidence on their trends for the years 1998-2010. We showed that the rate of hiring and job separation declined dramatically over that time frame, with evidence of a clear stair-step pattern during recessions. We explored jobs that lasted a single quarter, and found that they too declined during that time period. We finally show that the job tenure distribution has shifted toward longer duration jobs.

The evidence on hires, separations, and single quarter jobs presented here comes from well-established publicly available statistics produced by the LEHD program. The description of the tenure statistics and the presentation of the tenure results here are first steps in an ongoing research and product development process.

\section{References}

Abowd, John M., Bryce E. Stephens, Lars Vilhuber, Fredrik Andersson, Kevin L. McKinney, Marc Roemer, and Simon Woodcock. 2009. "The LEHD Infrastructure Files and the Creation of the Quarterly Workforce Indicators." In Producer Dynamics, ed. Timothy Dunne, J. Bradford Jensen, and Mark J. Roberts. Chicago, IL: University of Chicago Press.

Abowd John M, and Lars Vilhuber. 2011. "National Estimates of Gross Employment and Job Flows from the Quarterly Workforce Indicators with Demographic and Industry Detail.” Journal of Econometrics, 161(1): 82-99.

Abraham, Katharine G., John Haltiwanger, Kristin Sandusky, and James R. Spletzer. 2013. "Exploring Differences in Household vs. Establishment Measures of Employment.” Journal of Labor Economics 31(2, pt. 2): S129-S172.

Benedetto, Gary, John Haltiwanger, Julia Lane, and Kevin McKinney. 2007. "Using Worker Flows to Measure Firm Dynamics." Journal of Business \& Economic Statistics 25(3): 299-313.

Davis, Steven J., R. Jason Faberman, John C. Haltiwanger, and Ian Rucker. 2010. "Adjusted Estimates of Worker Flows and Job Openings in JOLTS." In Labor in the New Economy, ed. Katharine G. Abraham, James R. Spletzer, and Michael J. Harper. Chicago, IL: University of Chicago Press.

Farber, Henry. 1999. "Mobility and Stability: The Dynamics of Job Change in Labor Markets.” In Handbook of Labor Economics, Vol. 3B, ed. by O. Ashenfelter and D. Card. Amsterdam: Elsevier, 2439-2484.

Fujita, Shigeru, and Giuseppe Moscarini. 2013. "Recall and Unemployment.” NBER Working Paper \#19640.

Haltiwanger, John, Henry Hyatt, Erika McEntarfer, Liliana Sousa, and Stephen Tibbets. 2014. "Firm Age and Size in the Longitudinal Employer-Household Dynamics Data." U.S. Census Bureau Center for Economic Studies Working Paper \#14-16. 
Hyatt, Henry and Erika McEntarfer. 2012. “Job-to-Job Flows and the Business Cycle.” U.S. Census Bureau Center for Economic Studies Working Paper \#12-04.

Hyatt, Henry R. and James R. Spletzer. 2013. "The Recent Decline in Employment Dynamics.” IZA Journal of Labor Economics, 2(5): 1-21.

Hyatt, Henry R., and James R. Spletzer. 2014. "The Recent Decline in Short Duration Jobs.” Paper presented at the 2014 Society of Labor Economists meeting in Arlington, VA.

Neumark, David, Daniel Polsky, and Daniel Hansen, 1999, "Has Job Stability Declined Yet? New Evidence for the 1990's," Journal of Labor Economics, pp. S29-64. Reprinted in David Neumark, Ed., 2000, On the Job: Is Long-Term Employment a Thing of the Past? (New York: Russell Sage Foundation), pp. 70-110. 
Figure 1: Hires and Separations in Survey and Administrative Records Sources Copied from Hyatt and Spletzer (2013)

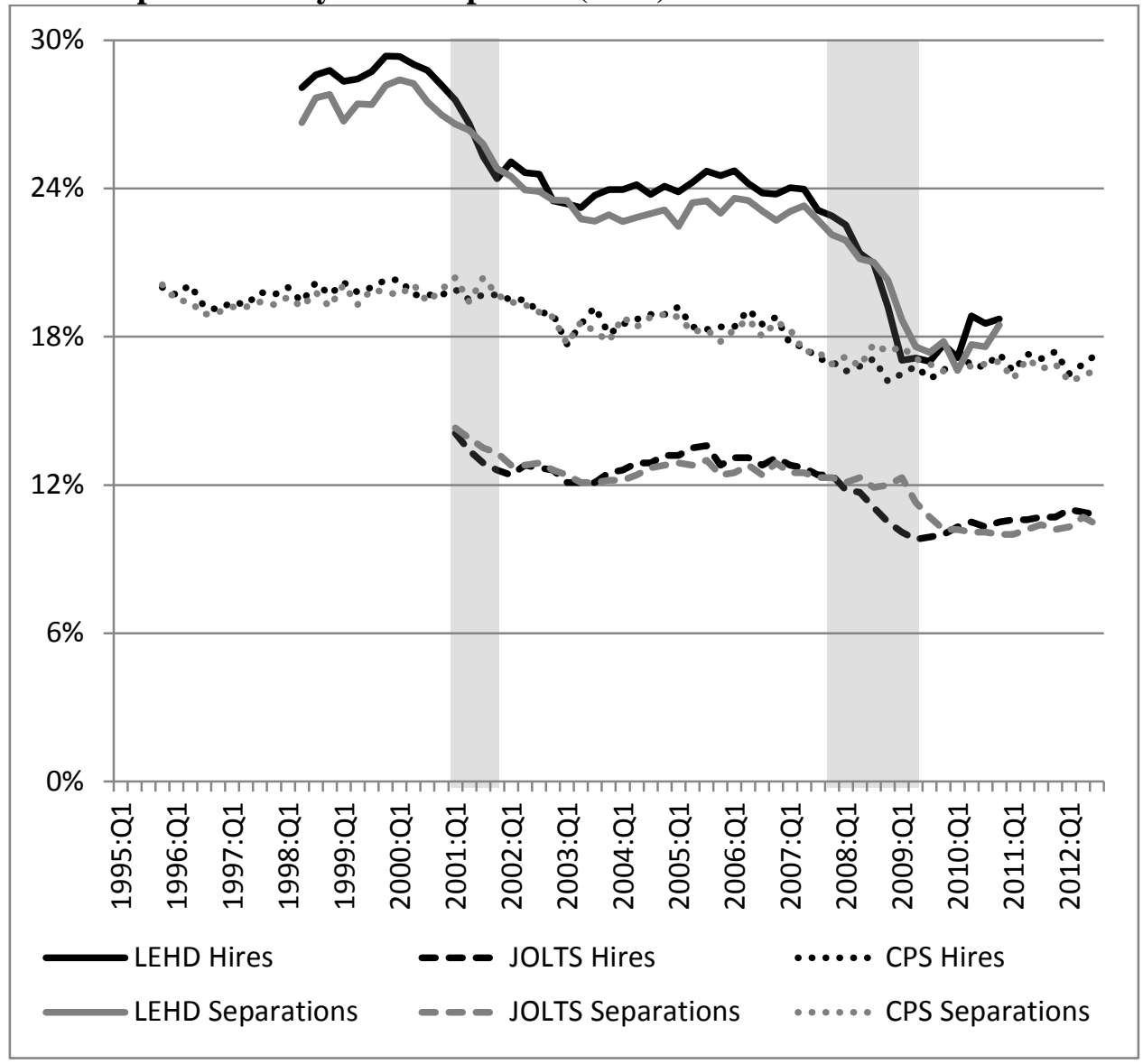

Notes: LEHD data for 30 states downloaded from the Cornell Virtual RDC. JOLTS national monthly data were downloaded from the BLS website and converted to a quarterly frequency. CPS national monthly data were downloaded from the Federal Reserve website and converted to a quarterly frequency. All data are seasonally adjusted. See Hyatt and Spletzer (2013) for additional details. 
Figure 2: Single Quarter Job Holding in the LEHD Data

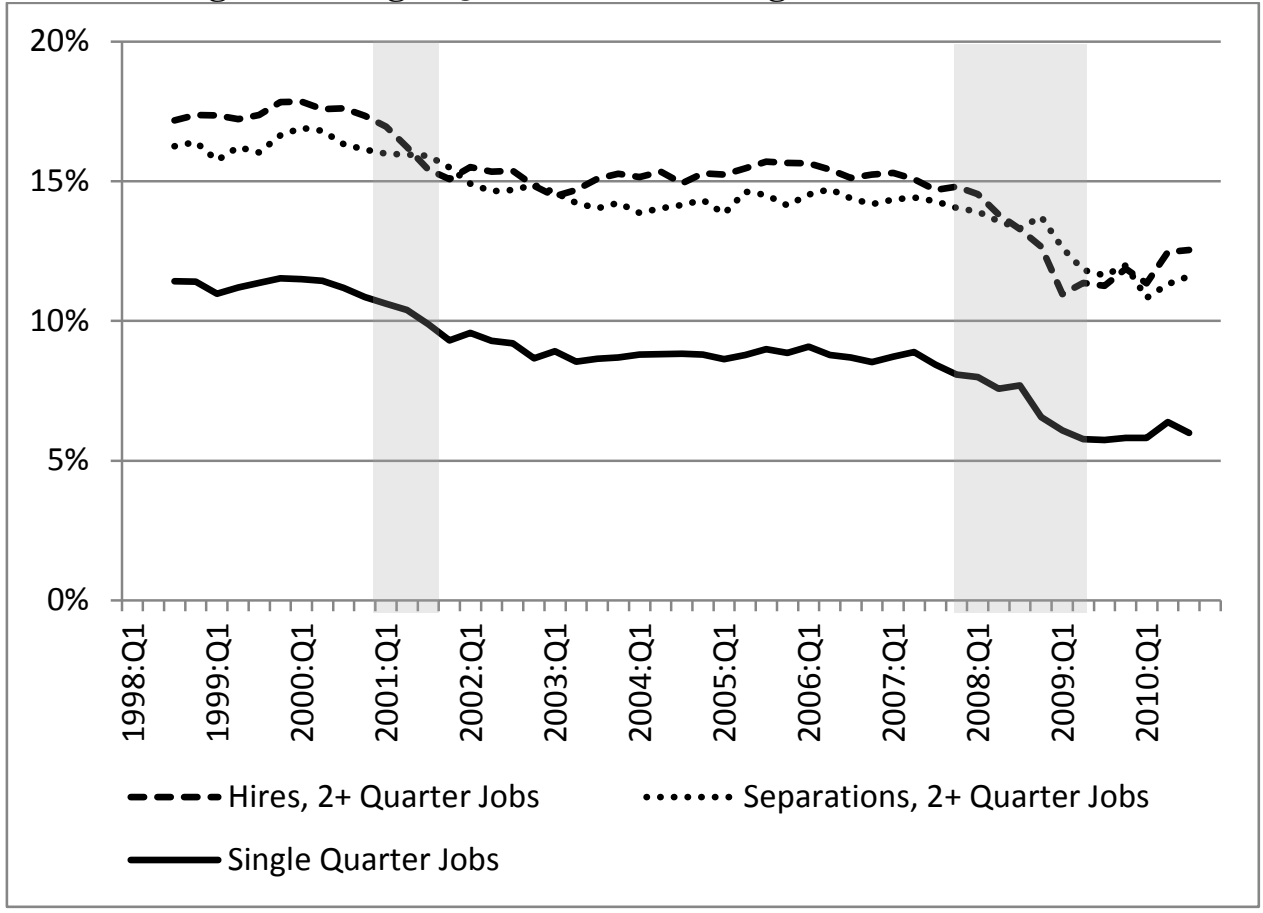

Notes: LEHD data for 30 states downloaded from the Cornell Virtual RDC. All data are seasonally adjusted. See text for additional details. 
Figure 3: Hires Rate and Tenure-Specific Separation Rates

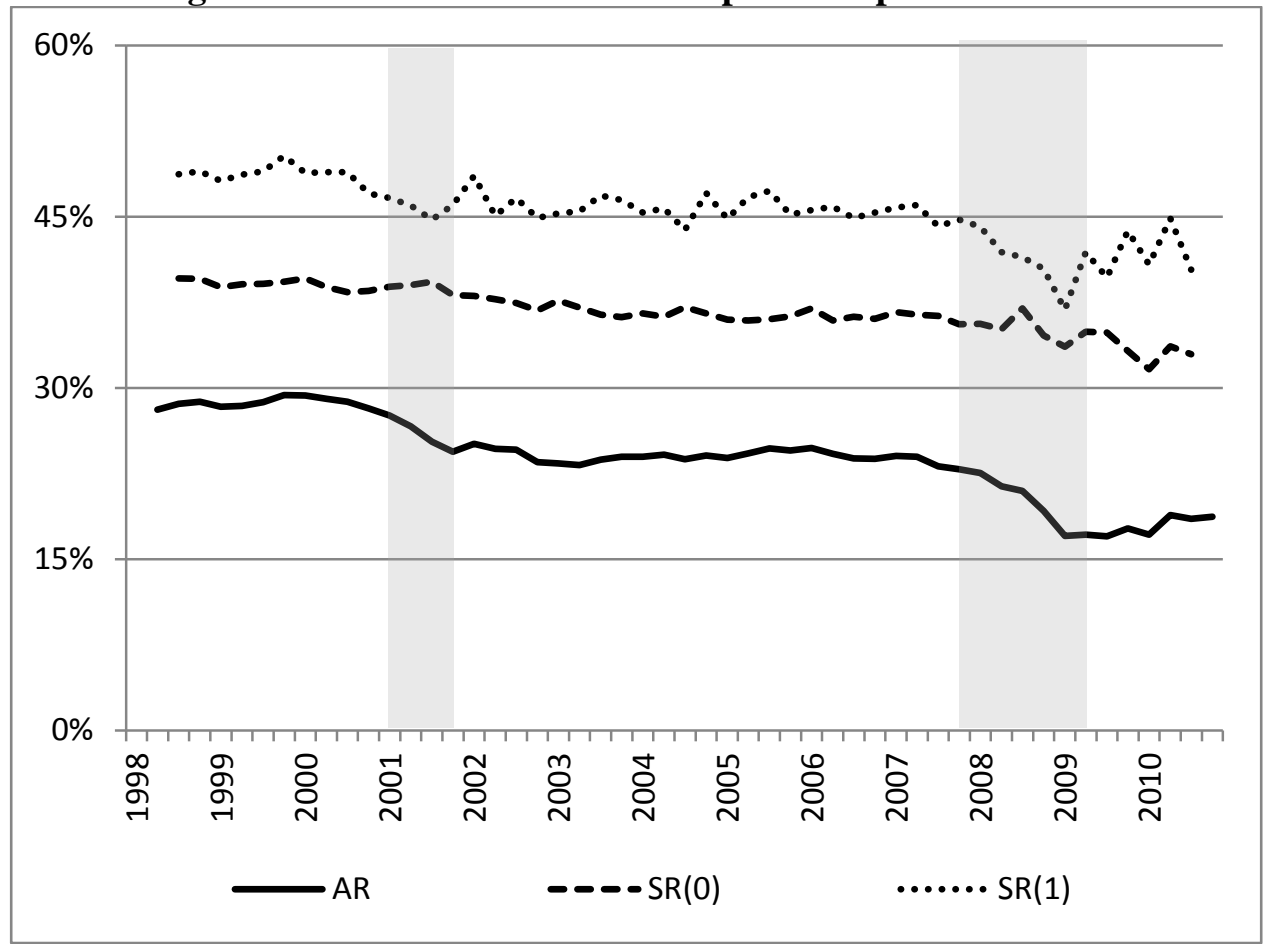

Notes: LEHD data for 30 states downloaded from the Cornell Virtual RDC. All data are seasonally adjusted. See text for additional details. 
Figure 4: Tenure Shares

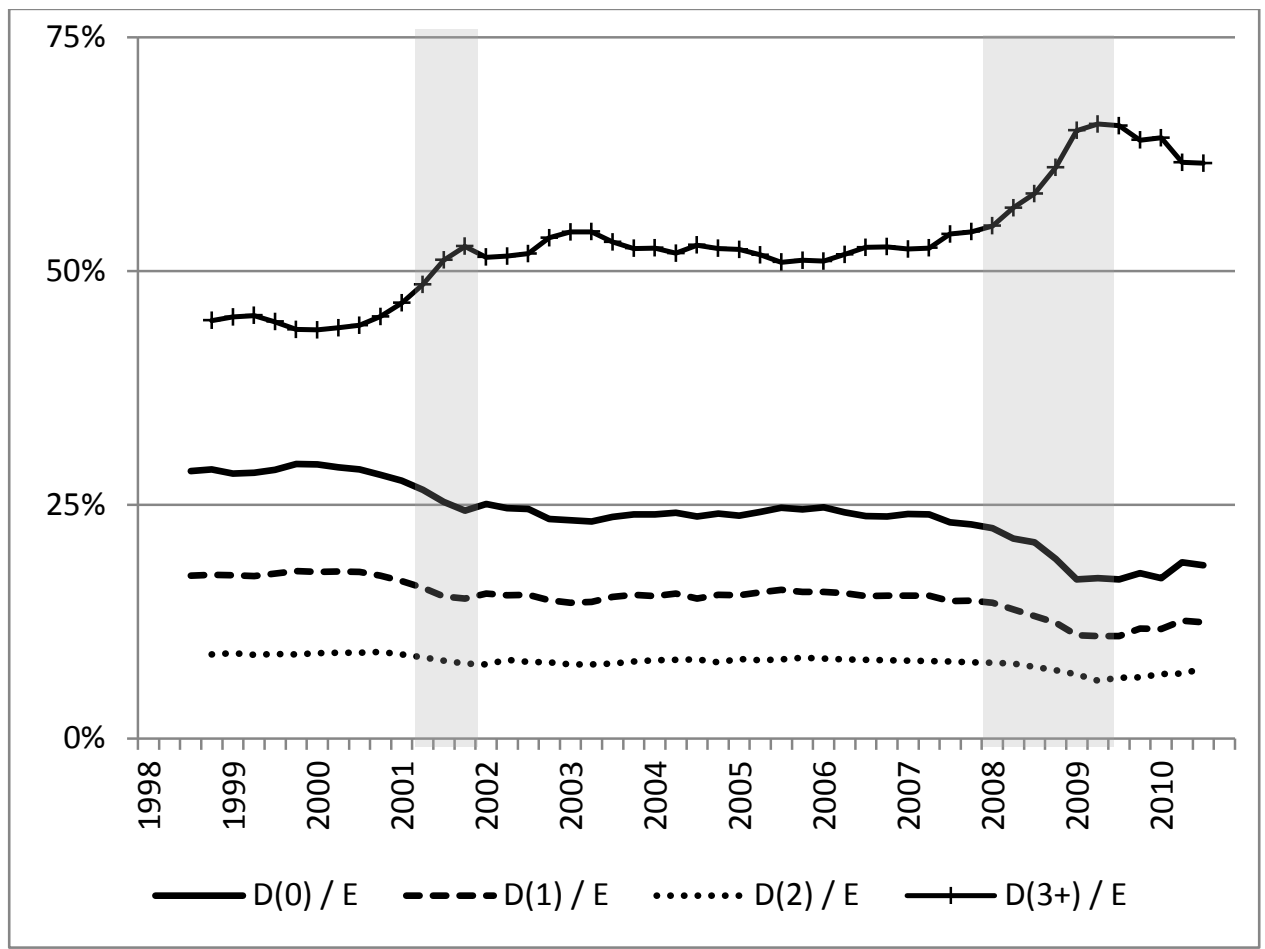

Notes: LEHD data for 30 states downloaded from the Cornell Virtual RDC. All data are seasonally adjusted. See text for additional details. 